\title{
Stable carbon and nitrogen isotopic compositions of sinking particles in the northeast Japan Sea
}

\author{
TAKAHIRo NAKANiShi* and MaSaO MinagaWA \\ Graduate School of Environmental Earth Science, Hokkaido University, \\ Kita-10, Nishi-5, Kita-ku, Sapporo 060-0810, Japan
}

(Received July 29, 2002; Accepted November 29, 2002)

\begin{abstract}
A sediment trap experiment and stable carbon and nitrogen isotope analysis of sinking organic particles have been performed in the northeast Japan Sea from August 1998 to October 1999 in order to confirm the relationship between seasonal variability of phytoplankton production and the isotope composition of sinking particles. The sediment trap deployed at $1090 \mathrm{~m}$ has successfully recovered samples recording organic particles sinking for a year round. Increases of POC and total mass fluxes suggested that blooming occur twice a year in late autumn and early summer in this region. It was shown that the seasonal variation of $\delta^{13} \mathrm{C}$ and $\delta^{15} \mathrm{~N}$ of sinking particles could be explained by the general pattern controlling isotope ratios of phytoplankton so that appearance of isotope fractionation on photosynthesis and nitrate uptake might play a most important role to change $\delta^{13} \mathrm{C}$ and $\delta^{15} \mathrm{~N}$ of phytoplankton in tightly linked with nutrient supply and production rate in the mixed layer.

The $\delta^{13} \mathrm{C}$ and $\delta^{15} \mathrm{~N}$ of the surface sediment were significantly heavier than those of sinking particles and showed a consistent trend of vertical isotopic change with the results reported in previous works. Compiled such vertical trend we addressed that carbon and nitrogen isotopic discrimination between sinking particles and the surface sediment might be qualified by the bottom depth due to isotope discrimination in sinking process but further modification can occur by regional factors such as import of allochthonous substances. Finally we stress about the implication of such factor to apply isotopic proxies to paleoceanographic research.
\end{abstract}

\section{INTRODUCTION}

The Japan Sea is a semi-enclosed marginal sea closely linking with two other marginal seas in the North Pacific Ocean; the Sea of Okhotsk and the East China Sea. Because of this geographical setting, geological researches using the Japan Sea sediments have often provided useful clue to understand periodic interaction within surrounding seas and the terrestrial environments throughout the late Quaternary period (Tada et al., 1999). Recently some studies using sediment core revealed that the Japan Sea has been faithfully influenced by the global eustacy change and suffered from the periodic exchange of anoxic/oxic condition in deep water between glacial-interglacial changes (Oba et al., 1991; Tada et al., 1999). In addition to such change, biological production seemed to vary with the relation to the impact of freshwater and Aeolian dust deposition from the continental land. Some studies based on bio-molecules and stable isotope analysis have already detected such evidences (Ishiwatari et al., 1994; Minoura et al., 1997; Okumura et al., 1996; Minagawa and Nakanishi, 2000), however, it has been limited to read more detail mechanism using some chemical signals in sediment core samples to certify such hypothesis based on only general knowledge of proxies, because of its unique oceanographic condition of the Japan Sea, for in- 
stance, having very shallow sill depth, forming of deep proper water and seasonally intensive dust fall from Loess plateau, etc. Therefore this work aimed to get more detail criteria to decode isotope compositions of carbon and nitrogen for organic matter as proxies of marine plankton production in the modern Japan Sea. Because it is quite difficult to perform field works throughout the year especially in winter, we intended to collect sinking particulate matters by sediment trap deployments and studied how the isotope composition can be varied in all year round. The focus is also given to evaluate the isotopic alteration in sinking and sedimentation. We have also studied about seasonal change of biomarker molecules on the relation to the phytoplankton variability using the same samples, and the result will be published in elsewhere (Nakanishi and Minagawa, in prep.).

The warm Tsushima Current flows into the Japan Sea through the Tsushima Strait (sill depth: $130 \mathrm{~m}$ ) and flows out through the Tsugaru (sill depth: $130 \mathrm{~m}$ ) and Soya Straits (sill depth: $55 \mathrm{~m}$ ). The Japan Sea Proper Water, characterized by low temperature $\left(0.1-0.3^{\circ} \mathrm{C}\right)$, low salinity $(34.0-34.1$ psu) and high dissolved oxygen $(>210 \mu \mathrm{M})$, occupies deep and bottom waters below the depth of 200-300 m (Gamo et al., 1986). This deep water is known to be formed by cooling of surface water in the northwestern region in winter. Although the Japan Sea is known as a unique ecosystem with a high productivity, there are only a few studies reporting its seasonal variation of phytoplankton activity at the semi-pelagic area (e.g., Nagata, 1993; Hirakawa et al., 1999). Fortunately the satellite images analysis gave excellent discovery showing seasonal variability of phytoplankton in the whole Japan Sea (Kim et al., 2000). It was reported that blooming has been appeared twice in spring and fall. The authors issued that the appearance would be controlled by the factor of mixed layer depth regarding to the nutrient supply. However, because no chemical observation has been executed to reveal the chemical structure in winter, it is not certified yet if such mechanism on nutrient supply can really control plankton production in the Japan Sea. Correspondence between variations of $\delta^{13} \mathrm{C}$ and $\delta^{15} \mathrm{~N}$ in sinking particles and seasonal variation of phytoplankton distribution may certify if these proxies can be useful to estimate surface water condition in the Japan Sea.

The stable carbon and nitrogen isotopic compositions in sinking POM have been measured in many regions, as useful tracers of biogeochemical processes in surface water. The $\delta^{13} \mathrm{C}$ value in sinking POC varies mainly by isotope fractionation associated with photosynthesis of phytoplankton, which is regulated by the growth rate, dissolved $\mathrm{CO}_{2}$ concentration and so on (Rau et al., 1989; Laws et al., 1995). There will be also affected by input of terrestrial organic matter from river and atmospheric transports. On the other hand, the nitrogen isotopic ratio in sinking PON is controlled by more complicated mechanisms. The $\delta^{15} \mathrm{~N}$ of phytoplankton depends not only on the isotope fractionation during uptake of substrates $\left(\mathrm{NO}_{3}^{-}\right.$, $\mathrm{NO}_{2}^{-}$, and $\mathrm{NH}_{4}^{+}$) but also on the isotopic composition of nitrogen constituent and the degree of nutrient utilization (Wada and Hattori, 1978; Altabet et al., 1991). Furthermore, another important process is the trophic transfer of nitrogen within food webs, where a stepwise increase in $\delta^{15} \mathrm{~N}$ with trophic level has been observed (Minagawa and Wada, 1984; Wada et al., 1987; Fry, 1988). These variations of each isotope ratio in biogeochemical processes are closely connected with physicochemical conditions (water circulation, temperature, light intensity, salinity, and others). These features of both carbon and nitrogen isotopes in sediments are also used as valuable tools in paleoceanographic studies (e.g., Jasper et al., 1994; Farrell et al., 1995; Nakatsuka et al., 1995; Francois et al., 1997), although isotopic effect on degradation during sinking of POM and diagenesis on a bottom surface is still remained as an unavoidable factor (Altabet et al., 1991; Nakatsuka et al., 1997).

In this study, we present the first result of $\delta^{13} \mathrm{C}$ and $\delta^{15} \mathrm{~N}$ of sinking particles in the Japan Sea. Based on the all year round observation of sinking particles, we reconstruct the seasonal varia- 


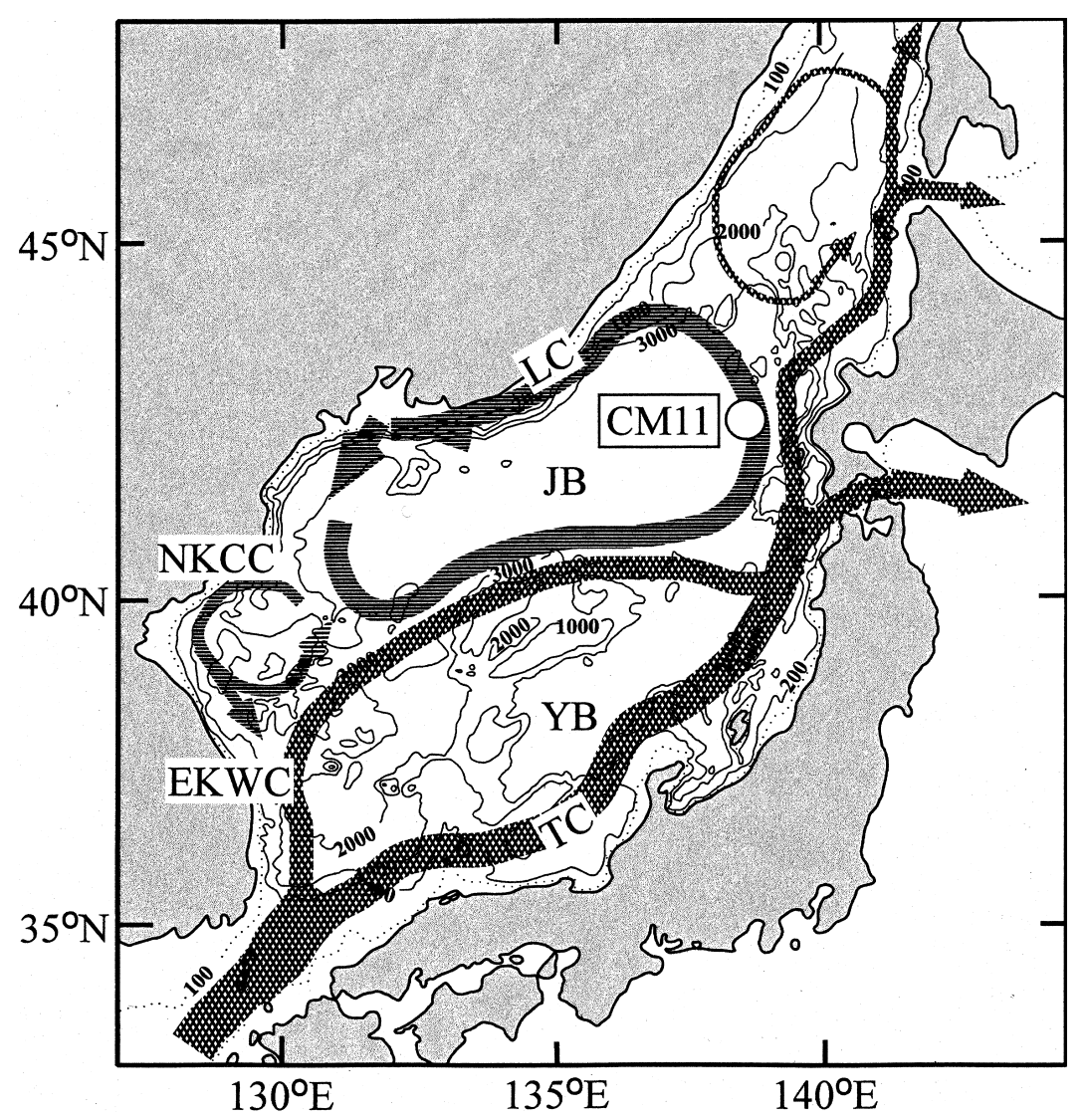

Fig. 1. Sampling location and main surface currents in the Japan Sea. Abbreviations are as follows: TC: the Tsushima Current, LC: the Liman Current, EKWC: the East Korean Warm Current, NKCC: the North Korean Cold Current, JB: the Japan Basin, and YB: the Yamato Basin (referred to Senjyu, 1999).

tion of biological production and attempt to estimate the nutrient dynamics which should be transmitted in the fluctuation in $\delta^{13} \mathrm{C}$ and $\delta^{15} \mathrm{~N}$ of organic particle. Finally we study the effect of degradation of sinking particle to the alteration of isotope composition in the water column and at the surface sediment and attempt to estimate the isotope discrimination factor between sinking particles and the surface sediment by compiling the data in previous works.

\section{MAterial AND MethodS}

The sediment trap mooring was located at the station CM11 on the eastern Japan Basin in the Japan Sea $\left(42^{\circ} 44^{\prime} \mathrm{N}, 138^{\circ} 17^{\prime} \mathrm{E}, 3665 \mathrm{~m}\right.$ depth:
Fig. 1) for about one year on August 1998 to October 1999. The trap was deployed and recovered in KH98-3 and KH99-4 cruises of the R/V Hakuho-Maru respectively. Sinking particle samples were collected on three layers; the upper trap (deployed at $1090 \mathrm{~m}$, McLane Mark VII with 20 receiving cups turning each 19.5-day intervals), the middle trap (at $1600 \mathrm{~m}$, Nichiyu-Giken-Kogyo Ltd. SMW13W-6000, with 13 cups turning each 30-day) and the lower trap (at $3110 \mathrm{~m}$, McLane Mark VII, with 20 cups turning each 19.5-day). Unfortunately, because of a mechanical malfunction, the traps of middle and lower layers stopped halfway and one cup (sample \#5) was lost in lower trap, so collected only 4 and 8 samples, respectively. Before deployment, the collecting cups 


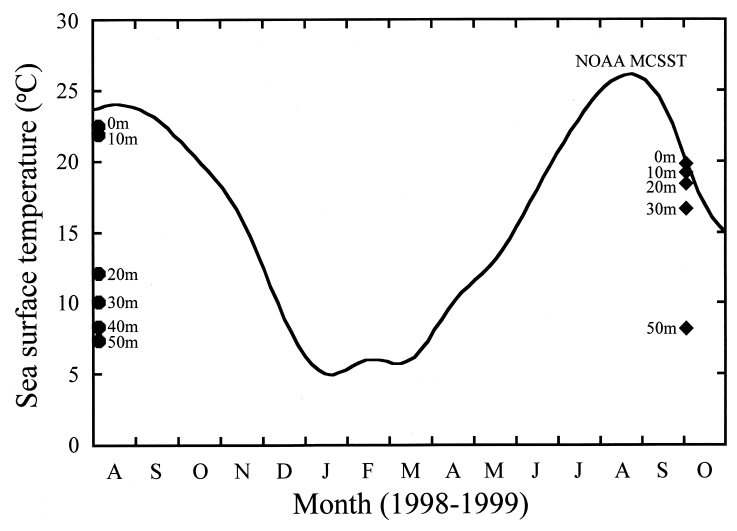

Fig. 2. Seasonal variation of the sea surface temperature at the trap site. Seasonal data are derived from NOAA MCSST. Water temperatures of surface layer in Aug. 4, 1998 (○) and Oct. 2, 1999 (•) were observed on ships.

were filled with 2.5 vol\% formaldehyde neutralized by sodium tetraborate (borax) and diluted with filtered seawater for sample preservation. Large particles including zooplankton and other swimmers were sieved off by a $1 \mathrm{~mm}$ mesh net and taken off carefully by hand picking. Then the sinking particles were filtered onto a precombusted $\left(450^{\circ} \mathrm{C}, 2 \mathrm{hr}\right)$ Whatman GF/F filters, washed well with deionized water to remove salts and stored at $-20^{\circ} \mathrm{C}$ until analysis. Surface sediment $(0-1 \mathrm{~cm})$ was collected by a multiple core samples at CM18 (same site of CM11) and was stored at $4^{\circ} \mathrm{C}$ until analysis.

Sinking particles and surface sediment were dried in an electric oven at $60^{\circ} \mathrm{C}$ and then the latter was crushed and sieved through a $250 \mu \mathrm{m}$ mesh. All samples were decarbonized using $1 \mathrm{M}$ $\mathrm{HCl}$, rinsed with deionized water to remove salts, and dried again. The carbon and nitrogen contents and isotopic ratios were determined by the flowinjection method using a Finnigan MAT 252 mass spectrometer connected with a Fisons NA1500 elemental analyzer. The isotopic ratio $\left({ }^{13} \mathrm{C} /{ }^{12} \mathrm{C}\right.$ and ${ }^{15} \mathrm{~N} /{ }^{14} \mathrm{~N}$ ) was calibrated according to working standards and is presented by the data notation:

$$
\begin{aligned}
& \delta^{13} \mathrm{C} \\
& =\left\{\left({ }^{13} \mathrm{C} /{ }^{12} \mathrm{C}\right)_{\text {sample }} /\left({ }^{13} \mathrm{C} /{ }^{12} \mathrm{C}\right)_{\text {standard }}-1\right\} \times 1000(\% \text { o })
\end{aligned}
$$

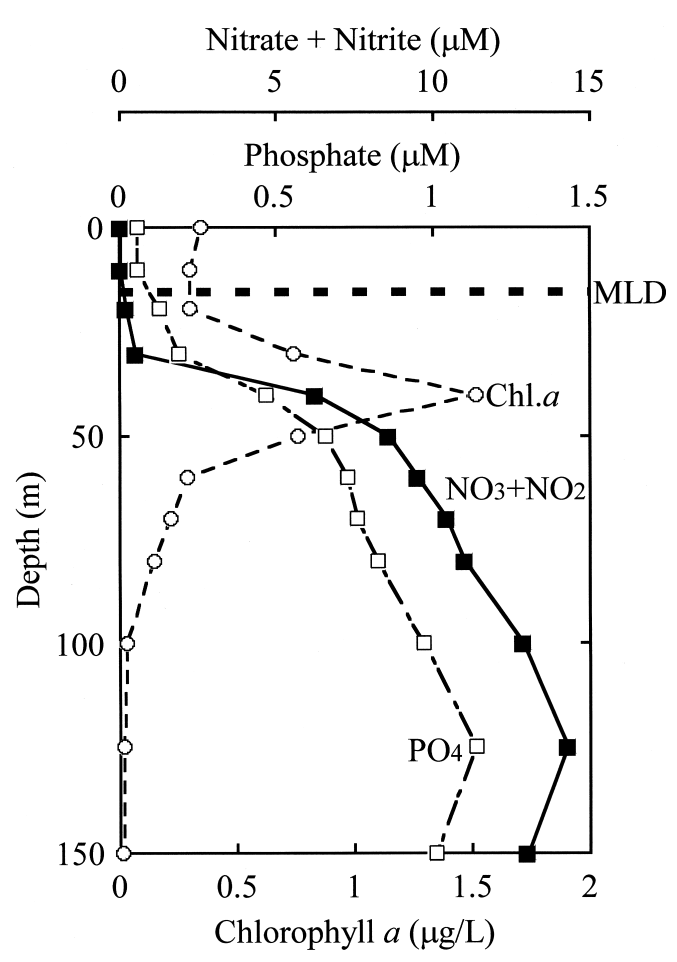

Fig. 3. Vertical profiles of nitrate + nitrite $(\mathbf{\square})$, phosphate $(\square)$, and chlorophyll a $(\bigcirc)$ at the trap site in Aug. 4, 1998 (Nozaki, 1998).

$$
\begin{aligned}
& \delta^{15} \mathrm{~N} \\
& =\left\{\left({ }^{15} \mathrm{~N} /{ }^{14} \mathrm{~N}\right)_{\text {sample }} /\left({ }^{15} \mathrm{~N} /{ }^{14} \mathrm{~N}\right)_{\text {standard }}-1\right\} \times 1000(\%)
\end{aligned} .
$$

Data were finally converted to the international presentation based on PDB and atmospheric $\mathrm{N}_{2}$ for carbon and nitrogen, respectively. The replicate error was estimated to be within $\pm 0.2 \%$ o for both $\delta^{13} \mathrm{C}$ and $\delta^{15} \mathrm{~N}$ by an amino acid reagent.

Water temperatures and salinity profiles were observed in two cruises on Aug. 4, 1998 (Nozaki, 1998) and Oct. 2, 1999 (Terazaki, 1999). However as any other observation data were not available, we estimated the seasonal variation of the sea surface temperature at the trap site was derived from NOAA MCSST satellite data (Fig. 2). Measured water temperatures at $0 \mathrm{~m}$ depth agreed well with that of the satellite (Fig. 2). Thus, the seasonal data by the satellite should be good appropriate in this study.

The nutrient and chlorophyll $a$ analyses were 


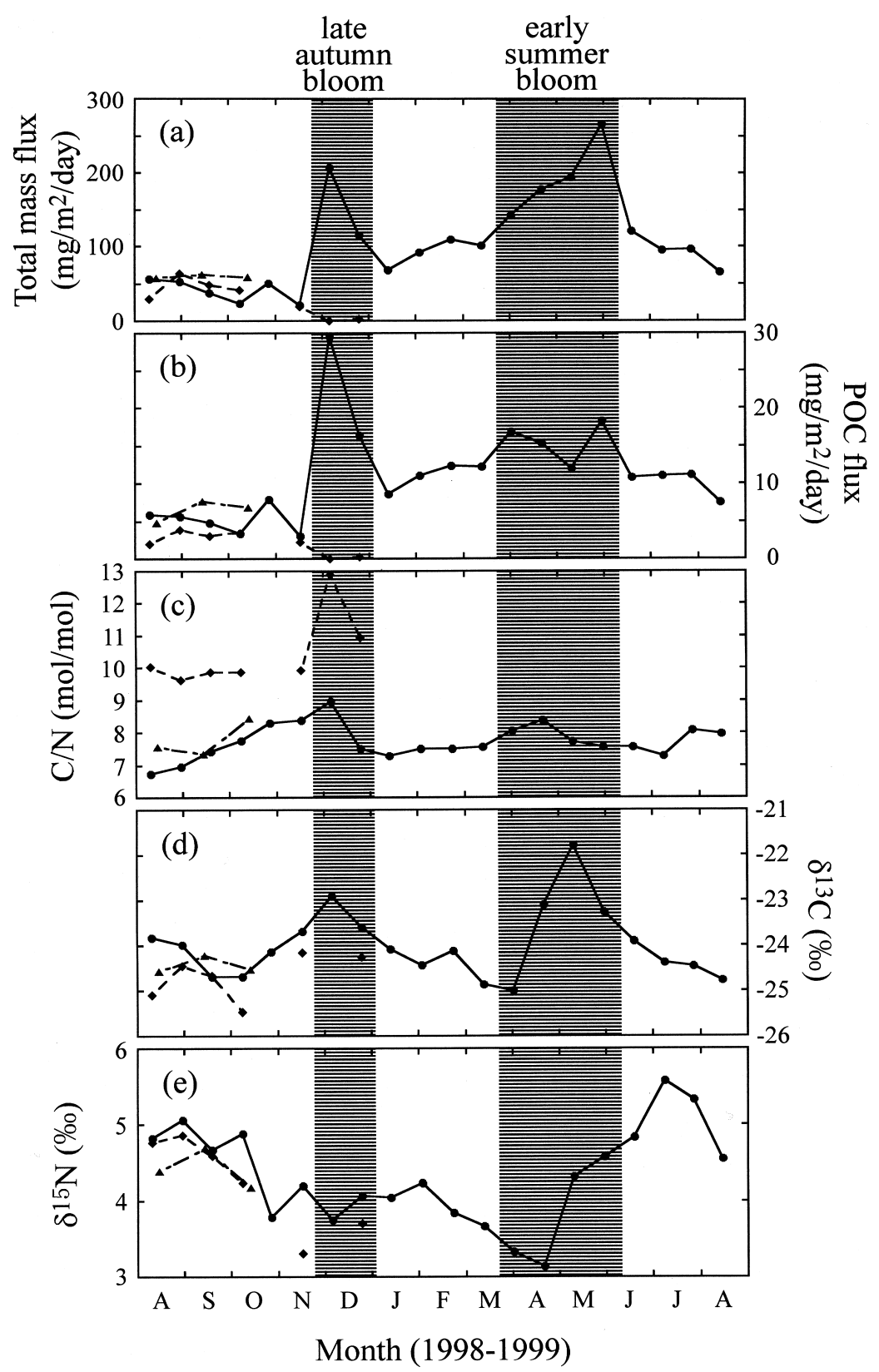

Fig. 4. Seasonal variations in (a) total mass flux, (b) POC flux, (c) C/N, (d) $\delta^{13} C$, and (e) $\delta^{15} N$. Marks denote difference of depths: the upper $(\mathbf{\bullet})$, the middle $(\mathbf{\Delta})$, and the lower trap $(\bullet)$.

done on ship in Aug. 4, 1998 (Nozaki, 1998: Fig. 3). Nitrate, nitrite, and phosphate of seawater samples were analyzed on the board by a rapid flow analyzer (ALPKEM PFA300) using ordinal colorimetric reactions; briefly cadmium reduction and subsequent azo dye method (absorbance maxi- mum, $543 \mathrm{~nm}$ ) for nitrite and nitrate, and molybdenum blue method $(880 \mathrm{~nm})$ for phosphate. The chlorophyll $a$ was also analyzed on the ship by the fluorescence spectrometry (Turner Design Model 110) using a Whatman GF/F filter after soaking with DMF solution. 


\section{RESULTS}

Analytical results on sinking particles are listed in Table 1 and the temporal variations are shown in Fig. 4. The total mass flux (dry weight base) in the upper trap ranged from 21 to $265 \mathrm{mg} / \mathrm{m}^{2} /$ day (annual average $108 \mathrm{mg} / \mathrm{m}^{2} /$ day) and showed two maxima in late autumn and early summer (Fig. 4a). The POC flux in the upper trap ranged from 3.1 to $29.5 \mathrm{mg} / \mathrm{m}^{2} /$ day (annual average $11.5 \mathrm{mg}$ /

Table 1. Results of isotopic and elemental analyses of sinking particles and the surface sediment

\begin{tabular}{|c|c|c|c|c|c|c|}
\hline Sample & Collection time & $\begin{array}{l}\text { Total mass flux } \\
\left(\mathrm{mg} / \mathrm{m}^{2} / \text { day }\right)\end{array}$ & $\begin{array}{c}\text { POC flux } \\
\left(\mathrm{mg} / \mathrm{m}^{2} / \text { day }\right)\end{array}$ & $\begin{array}{c}\mathrm{C} / \mathrm{N} \\
(\mathrm{mol} / \mathrm{mol})\end{array}$ & $\begin{array}{l}\delta^{13} \mathrm{C} \\
(\% o)\end{array}$ & $\begin{array}{l}\delta^{15} \mathrm{~N} \\
(\% o)\end{array}$ \\
\hline \multicolumn{7}{|c|}{ Upper (1090 m) } \\
\hline 1 & 01/08/98-20/08/98 & 57 & 5.9 & 6.8 & -23.8 & 4.8 \\
\hline 2 & 20/08/98-09/09/98 & 53 & 5.7 & 7.0 & -24.0 & 5.1 \\
\hline 3 & 09/09/98-28/09/98 & 38 & 4.8 & 7.4 & -24.7 & 4.7 \\
\hline 4 & 28/09/98-18/10/98 & 24 & 3.4 & 7.8 & -24.7 & 4.9 \\
\hline 5 & 18/10/98-06/11/98 & 51 & 7.9 & 8.3 & -24.1 & 3.8 \\
\hline 6 & 06/11/98-26/11/98 & 21 & 3.1 & 8.4 & -23.7 & 4.2 \\
\hline 7 & $26 / 11 / 98-15 / 12 / 98$ & 208 & 29.5 & 9.0 & -22.9 & 3.8 \\
\hline 8 & 15/12/98-04/01/99 & 116 & 16.4 & 7.5 & -23.6 & 4.1 \\
\hline 9 & 04/01/99-23/01/99 & 68 & 8.6 & 7.3 & -24.1 & 4.1 \\
\hline 10 & 23/01/99-12/02/99 & 92 & 11.1 & 7.5 & -24.4 & 4.2 \\
\hline 11 & 12/02/99-03/03/99 & 110 & 12.3 & 7.5 & -24.1 & 3.8 \\
\hline 12 & 03/03/99-23/03/99 & 102 & 12.2 & 7.6 & -24.9 & 3.7 \\
\hline 13 & 23/03/99-11/04/99 & 143 & 16.9 & 8.1 & -25.0 & 3.3 \\
\hline 14 & 11/04/99-01/05/99 & 178 & 15.4 & 8.4 & -23.1 & 3.1 \\
\hline 15 & 01/05/99-20/05/99 & 195 & 12.1 & 7.7 & -21.8 & 4.3 \\
\hline 16 & 20/05/99-09/06/99 & 265 & 18.2 & 7.6 & -23.3 & 4.6 \\
\hline 17 & 09/06/99-28/06/99 & 121 & 10.9 & 7.6 & -23.9 & 4.8 \\
\hline 18 & 28/06/99-18/07/99 & 95 & 11.1 & 7.3 & -24.4 & 5.6 \\
\hline 19 & 18/07/99-06/08/99 & 97 & 11.2 & 8.1 & -24.5 & 5.3 \\
\hline 20 & 06/08/99-25/08/99 & 66 & 7.6 & 8.0 & -24.8 & 4.6 \\
\hline \multicolumn{2}{|c|}{ annual mean } & 108 & 11.5 & 7.8 & -23.8 & 4.2 \\
\hline \multicolumn{7}{|c|}{ Middle (1600 m) } \\
\hline 1 & 01/08/98-30/08/98 & 58 & 4.8 & 7.6 & -24.6 & 4.4 \\
\hline 2 & $30 / 08 / 98-29 / 09 / 98$ & 63 & 7.7 & 7.4 & -24.2 & 4.7 \\
\hline 3 & 29/09/98-29/10/98 & 58 & 6.8 & 8.4 & -24.5 & 4.2 \\
\hline 4 & 29/10/98-02/10/99 & 120 & 14.1 & 8.4 & -23.6 & 5.1 \\
\hline \multicolumn{2}{|c|}{ annual mean } & 110 & 12.9 & 8.4 & -23.6 & 5.1 \\
\hline \multicolumn{7}{|c|}{ Lower (3110 m) } \\
\hline 1 & 01/08/98-20/08/98 & 29 & 2.0 & 10.0 & -25.1 & 4.8 \\
\hline 2 & 20/08/98-09/09/98 & 64 & 3.9 & 9.6 & -24.4 & 4.9 \\
\hline 3 & 09/09/98-28/09/98 & 48 & 3.0 & 9.9 & -24.7 & 4.6 \\
\hline 4 & 28/09/98-18/10/98 & 42 & 3.5 & 9.9 & -25.5 & 4.2 \\
\hline 5 & 18/10/98-06/11/98 & - & - & - & - & - \\
\hline 6 & 06/11/98-26/11/98 & 19 & 2.2 & 9.9 & -24.2 & 3.3 \\
\hline 7 & $26 / 11 / 98-15 / 12 / 98$ & 0 & 0.0 & 12.9 & - & - \\
\hline 8 & 15/12/98-04/01/99 & 2 & 0.3 & 10.9 & -24.2 & 3.7 \\
\hline 9 & 04/01/99-02/10/99 & 3 & 0.3 & 10.1 & -24.3 & 3.5 \\
\hline \multicolumn{2}{|c|}{ annual mean } & 9 & 0.8 & 9.9 & -24.7 & 4.0 \\
\hline \multicolumn{2}{|c|}{ Surface sediment (3665 m) } & - & - & 9.4 & -22.0 & 6.8 \\
\hline
\end{tabular}


$\mathrm{m}^{2} /$ day) and showed two maxima although the early summer peak was not as remarkable as found in the total flux (Fig. 4b). The $\mathrm{C} / \mathrm{N}$ atomic ratios varied between 6.8 and 9.0 (annual average 7.8) in the upper trap and showed higher values (9.612.9) in the lower trap (Fig. 4c). The $\delta^{13} \mathrm{C}$ values ranged from -25.0 to $-21.8 \%$ (annual fluxweighted average $-23.8 \%$ ) in the upper trap and there were higher values in late autumn and early summer (Fig. 4d). The $\delta^{15} \mathrm{~N}$ values ranged from 3.1 to $5.6 \%$ (annual flux-weighted average $4.2 \%$ ) in the upper trap and showed lower values from late autumn to early summer (Fig. $4 \mathrm{e}$ ). The $\delta^{13} \mathrm{C}$ and $\delta^{15} \mathrm{~N}$ values in the lower trap gave slightly lower values than that of the upper trap in compared with samples collected at same time. Surface sediment at the same site was found to enrich ${ }^{13} \mathrm{C}$ and ${ }^{15} \mathrm{~N}$ in compared to annual mean $\delta^{13} \mathrm{C}$ and $\delta^{15} \mathrm{~N}$ of sinking particles (Table 1 and Fig. 5), suggesting that diagenetic alteration during sinking and/or sedimenting of particles on the sea floor might change isotope compositions.

\section{Discussion}

Seasonal variability of $\delta^{13} C$ and $\delta^{15} N$ in sinking particles

Generally, phytoplankton production is enhanced two times per year in temperate zone due to combination of solar radiance and vertical water mixing (Parsons et al., 1984). In the Japan Sea this production pattern seems to be a case, because blooming has also observed twice a year based on the chlorophyll color observation by satellite (e.g., Kim et al., 2000). Total particle mass and POC fluxes obtained here seem to evidence such seasonal variation of biological activity (Fig. 4). In addition, other proxies such as lipid composition representing phytoplankton assemblages have indicated that diatom and dinoflagellate had multiplied in late autumn and early summer (Nakanishi and Minagawa, in prep.).

The temporal variation of $\delta^{13} \mathrm{C}$ in POC might be correlated with seasonal change of the growth rates of phytoplankton (Fig. $4 \mathrm{~d}$ ). The ${ }^{13} \mathrm{C}$ content in plankton increases when the production rate is fast because the isotopic fractionation is suppressed due to $\mathrm{CO}_{2}$ depletion for $\mathrm{CO}_{2}$ uptake (Laws et al., 1995). This interpretation has tested by both in laboratory and field observations, and has been successfully applied in the other regions (Nakatsuka et al., 1997; Wu et al., 1999). Temporal variations of $\mathrm{POC}$ and $\delta^{13} \mathrm{C}$ represent that $\delta^{13} \mathrm{C}$ of sinking particles increased in late autumn and early summer bloomings. Therefore, it seems that the variability of $\delta^{13} \mathrm{C}$ of sinking POC might be caused by variation of the isotope effect related to phytoplankton growth. Moreover, Fig. 4 shows
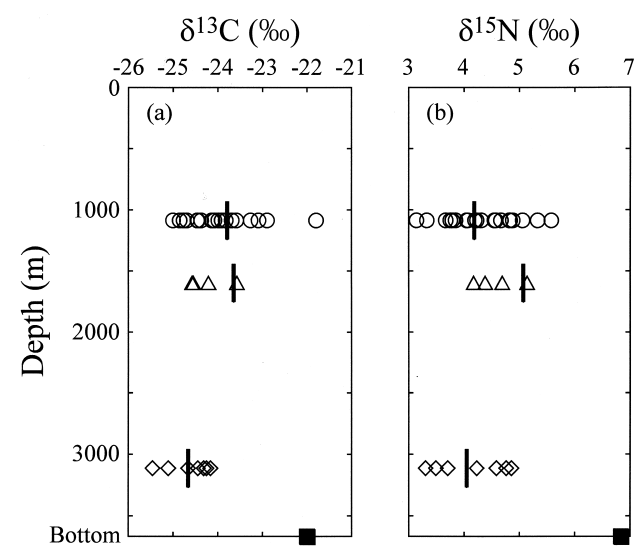

$\mathrm{C} / \mathrm{N}(\mathrm{mol} / \mathrm{mol})$

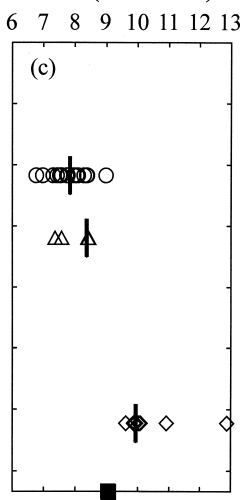

Fig. 5. Vertical variations in (a) $\delta^{13} C$, (b) $\delta^{15} N$, and (c) C/N. Marks denote difference of depths: the upper (O), the middle $(\triangle)$, the lower trap $(\diamond)$, and surface sediment $(\mathbf{\square})$. Perpendicular lines $(\mid)$ represent the annual fluxweighted averages of each trap. 


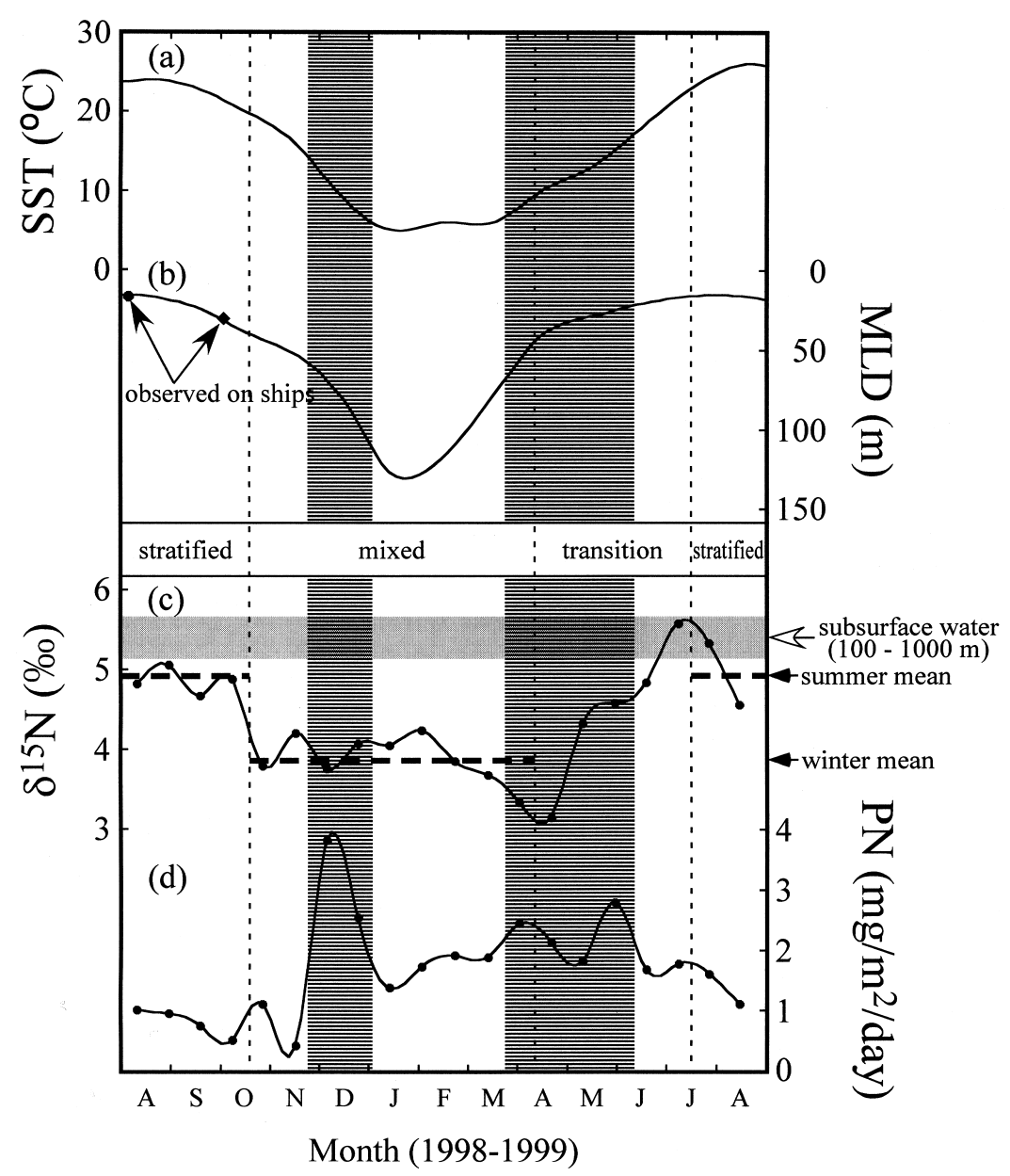

Fig. 6. The relationship between seasonal variations in $S S T, M L D, \delta^{15} N$, and PN flux. MLD is estimated based on monthly mean profiles of temperature from JODC Data Online Service System. MLD in Aug. (৩) and Oct. ( was observed on ships. Shaded area is $\delta^{15} \mathrm{~N}$ of subsurface water in the Japan Sea (Ohashi, 1999).

that $\delta^{13} \mathrm{C}$ in early summer was much heavier than that in late autumn although primary production might be relatively moderate in early summer inferred from POC flux. This difference is explained by following two reasons. Apparent isotope fractionation on $\mathrm{CO}_{2}$ uptake might be amplified in light limiting condition than that in nutrient limiting condition as shown in late autumn and early summer, respectively. Another reason might be ascribed to the seasonal change of phytoplankton assemblages. By the biomarker study, it has been revealed that diatom was the predominant phytoplankton in early summer whereas diatoms, dinoflagellates and haptophytes were symbiotically alive in late autumn (Nakanishi and Minagawa, in prep.). Such difference of living organisms would cause the apparent isotope fractionation factor associated with carbon fixation.

Terrestrial organic matter may influence $\delta^{13} \mathrm{C}$ of sinking POC if the input flux could be relatively larger compared with marine plankton production. In fact, Aeolian dust (Kosa) from Chinese continent is seasonally supplying terrestrial materials around entire Northeast Asia and the North Pacific in spring (Iwasaka et al., 1983). Consequently, lowering of $\delta^{13} \mathrm{C}$ in POC should be recorded for POC in spring because $\delta^{13} \mathrm{C}$ of ter- 
restrial plant is generally as lighter as $-26 \%$. The observed $\delta^{13} \mathrm{C}$ fell down from -23 to $-25 \%$ o from winter to spring. However this was not regarded to influence of terrestrial organic matter because $\mathrm{C} / \mathrm{N}$ ratios of same samples were not rise as expected to terrestrial organics of which $\mathrm{C} / \mathrm{N}$ ratios should be larger than 15 (Stein, 1991).

The $\delta^{15} \mathrm{~N}$ values of sinking particles in the upper trap showed a temporal variation ranging from $3.8 \%$ in October to April and to $4.9 \%$ in May to September (Fig. 4e). This seasonal variation on $\delta^{15} \mathrm{~N}$ might be caused by the transitional change of nutrient utilization and the related isotopic fractionation in the mixed layer (Fig. 6). The water depth of mixed layer (MLD) was observed to be $16 \mathrm{~m}$ and $30 \mathrm{~m}$ on Aug. 4, 1998, and Oct. 2, 1999 , respectively. The annual change of MLD can be estimated based on monthly mean vertical profiles of water temperature at the one degree square region including the trap experiment station (Fig. 6b, drawn using JODC Data Online Service System). The MLD at the site should deepen down to $100 \mathrm{~m}$ during December and February, while a strong stratification is formed at the depth shallower than $40 \mathrm{~m}$ during summer and autumn. The nutrient analysis showed that the nitrate showed as low as $0.1 \mu \mathrm{M}$ in surface water and about 25 $\mu \mathrm{M}$ in the deep water (Fig. 3). The subsurface water (100-1000 m water depth) in the Japan Sea has nitrate of which $\delta^{15} \mathrm{~N}$ is $5.4 \pm 0.2 \%$ (Ohashi, 1999). The $\delta^{15} \mathrm{~N}$ of trap samples showed relatively heavier values in summer and lower values in winter and spring. Relatively light $\delta^{15} \mathrm{~N}$ in winter can be explained by the nitrogen isotope fractionation in nitrate uptake by phytoplankton under the nitrate repleted condition, because progressive increase of MLD would continuously supply nitrate from the deeper water. On the other hand, the nitrate supply to the surface layer was inhibited by a rise of the pycnocline from spring to summer, and then nitrate depletion might occur in summer (Fig. 6b). Consequently, the $\delta^{15} \mathrm{~N}$ of phytoplankton became close to the value of nitrate in subsurface water, because the isotope fractionation could not work when phytoplankton utilized diffused nitrate from subsurface water.
From spring to summer, because the mixed layer gradually rises and prevents nitrate supply from deep layer, the euphotic layer becomes a semi-closed condition on nitrate. The variation of $\delta^{15} \mathrm{~N}$ in such a semi-closed system has been studied by several previous works in the northern North Pacific (Nakatsuka and Handa, 1997) and in the subarctic northeast Pacific (Wu et al., 1999). The $\delta^{15} \mathrm{~N}$ of sinking particles from spring to summer in present observation might be controlled by the Rayleigh fractionation model (Mariotti et al., 1981) as used by such studies. The stepwise increase of $\delta^{15} \mathrm{~N}$ observed on April to July might be interpreted by the isotope fractionation caused by such drawdown effect of nitrate in surface layer (Fig. 6).

An extremely high sinking flux was found for POC, PN and total mass weight in December (Figs. 4 and 6). However, obvious change of $\delta^{15} \mathrm{~N}$ was not recorded in the same time. It is presumed that the isotope effect on the nitrate uptake could be kept steady throughout this blooming event, meaning that sufficient amount of nitrate should be supported from the lower layer by vertical mixing. The nitrate concentration in summer was observed to be about $0 \mu \mathrm{M}$ at surface $20 \mathrm{~m}$ and gradually increased to $13 \mu \mathrm{M}$ at $100 \mathrm{~m}$ as shown in Fig. 3 . The MLD goes down from $50 \mathrm{~m}$ to $100 \mathrm{~m}$ on November to late December (Fig. 6b). This rapid change of MLD probably resulted the increment of nitrate concentration in the surface layer (100 $\mathrm{m})$. For instance, supposing the mixing of two water layers; the surface $50 \mathrm{~m}$ layer having $0 \mu \mathrm{M}$ nitrate and the lower water (50-100 m) with about $10.6 \mu \mathrm{M}$ nitrate would rise up to at least $5 \mu \mathrm{M}$ in the surface layer. It is emphasized that such increment of nitrate could induce rapid growth of phytoplankton as shown on December. Under such condition, the isotope effect associated with nitrate uptake was kept unchanged suggesting that the uptake rate of nitrate should be kept apparently constant. We believe that a growth condition such as a continuous-culture might take place in this period.

The sinking flux of PN decreased shortly in January (Fig. 6). It is presumed that strengthen- 
ing of the winter monsoon may cause limitation of solar radiation to the sea surface. After the depression of production, the $\delta^{15} \mathrm{~N}$ of PN seems to decrease gradually from January to April. The most likely reason is that the isotope fractionation in nitrate uptake might be extended because the nitrate concentration should be maximized in this period. An alternative explanation is ascribed to the seasonal change of phytoplankton species. Analyses of species-specific biomarkers showed temporal increase of fucosterol and campesterol suggesting that diatom was predominant in this time (Nakanishi and Minagawa, in prep.). Montoya and McCarthy (1995) suggested that diatoms might discriminate ${ }^{15} \mathrm{~N}$ during growth on $\mathrm{NO}_{3}{ }^{-}$more strongly than flagellates.

Alternative factors affecting $\delta^{15} \mathrm{~N}$ of PN are the isotope fractionation on the tropho-dynamics involved in the food chain (Minagawa and Wada, 1984; Wada et al., 1987; Altabet, 1988; Fry, 1988). Altabet (1988) explained that the variability of $\delta^{15} \mathrm{~N}$ of sinking particles and suspended matter might depend on the complexity of the food chain. Generally, as zooplankton enriches ${ }^{15} \mathrm{~N}$ in the tissues by isotope fractionation on feeding, the organic debris should play a role to increase $\delta^{15} \mathrm{~N}$. On the other hand, the excreted nitrogen from zooplankton is known to become lower in $\delta^{15} \mathrm{~N}$ than that of dietary nitrogen (Checkley and Entzeroth, 1985; Checkley and Miller, 1986), and serves as a substrate for phytoplankton growth. Hence, if the sinking particles are supported by zooplankton debris or fecal pellets, the $\delta^{15} \mathrm{~N}$ of sinking particle would change toward opposite ways. The biomass of zooplankton seems to increase on December and whole summer season. However there was not significant $\delta^{15} \mathrm{~N}$ signal observed in winter, indicating that the sinking particle essentially reflects mainly $\delta^{15} \mathrm{~N}$ of phytoplankton as a diet for zooplankton in surface layer but not of zooplankton debris. The gradual lowering in $\delta^{15} \mathrm{~N}$ from February to April may suggest isotopic change in nitrate in mixed layer as influenced by nitrogen excreted from zooplankton in surface layer.
Diagenetic alteration of $\delta^{13} C$ and $\delta^{15} N$

Altabet et al. (1991) reported that $\delta^{15} \mathrm{~N}$ of sinking particles is decreasing with depth. Same downward trend was also found in $\delta^{13} \mathrm{C}$ of sinking POC at the North Pacific (Nakatsuka et al., 1997). Nakatsuka et al. (1997) suggested that these variations in depth might be caused by selective degradation of molecules rich in ${ }^{13} \mathrm{C}$ and ${ }^{15} \mathrm{~N}$ such as amino acids. In this study, the sinking particle of deeper traps showed relatively larger $\mathrm{C} / \mathrm{N}$ ratio (Fig. 4c), suggesting that preferential degradation of organic matter may occur in sinking and change $\mathrm{C} / \mathrm{N}$. However, isotopic shift in carbon and nitrogen along the depth was relatively small as $0.6 \pm$ 0.4 and $0.4 \pm 0.3 \%$ o respectively between the upper and the deepest traps as compared within samples collected at same period. Nevertheless relatively small change in water column, the isotopic change between sinking particles and surface sediment was evidently found (Fig. 5). Therefore it is presumed that the diagenetic alteration of carbon and nitrogen isotopes is significant on the bottom or near the bottom layer but not in the water column.

The $\delta^{13} \mathrm{C}$ and $\delta^{15} \mathrm{~N}$ of surface sediment at the same site were -22.0 and $6.8 \%$, respectively. The increments of each isotopic ratio from annual fluxweighted average of the upper trap samples to the sediment exhibited +1.8 and $+2.6 \%$ for $\delta^{13} \mathrm{C}$ and $\delta^{15} \mathrm{~N}$ respectively (Fig. 5). Such enrichment processes of ${ }^{13} \mathrm{C}$ and ${ }^{15} \mathrm{~N}$ into sediments compared to sinking particles have been reported by many workers at various regions (e.g., Altabet and Francois, 1994; Fischer and Wefer, 1996; Nakatsuka et al., 1997; Fischer et al., 1998; Sigman et al., 1999). Figure 7 shows the compilation of previously reported isotopic fractionation between sinking particles and surface sediments for $\delta^{13} \mathrm{C}$ and $\delta^{15} \mathrm{~N}$. The $\Delta^{13} \mathrm{C}$ and $\Delta^{15} \mathrm{~N}$ values in Fig. 7 are defined as increments of $\delta^{13} \mathrm{C}$ and $\delta^{15} \mathrm{~N}$ from sinking particles to surface sediments. Several environmental factors such as water temperature, strength of oxidation condition, and sedimentation rate can cause the isotopic variability. The $\delta^{13} \mathrm{C}$ of surface sediment and sinking particles 


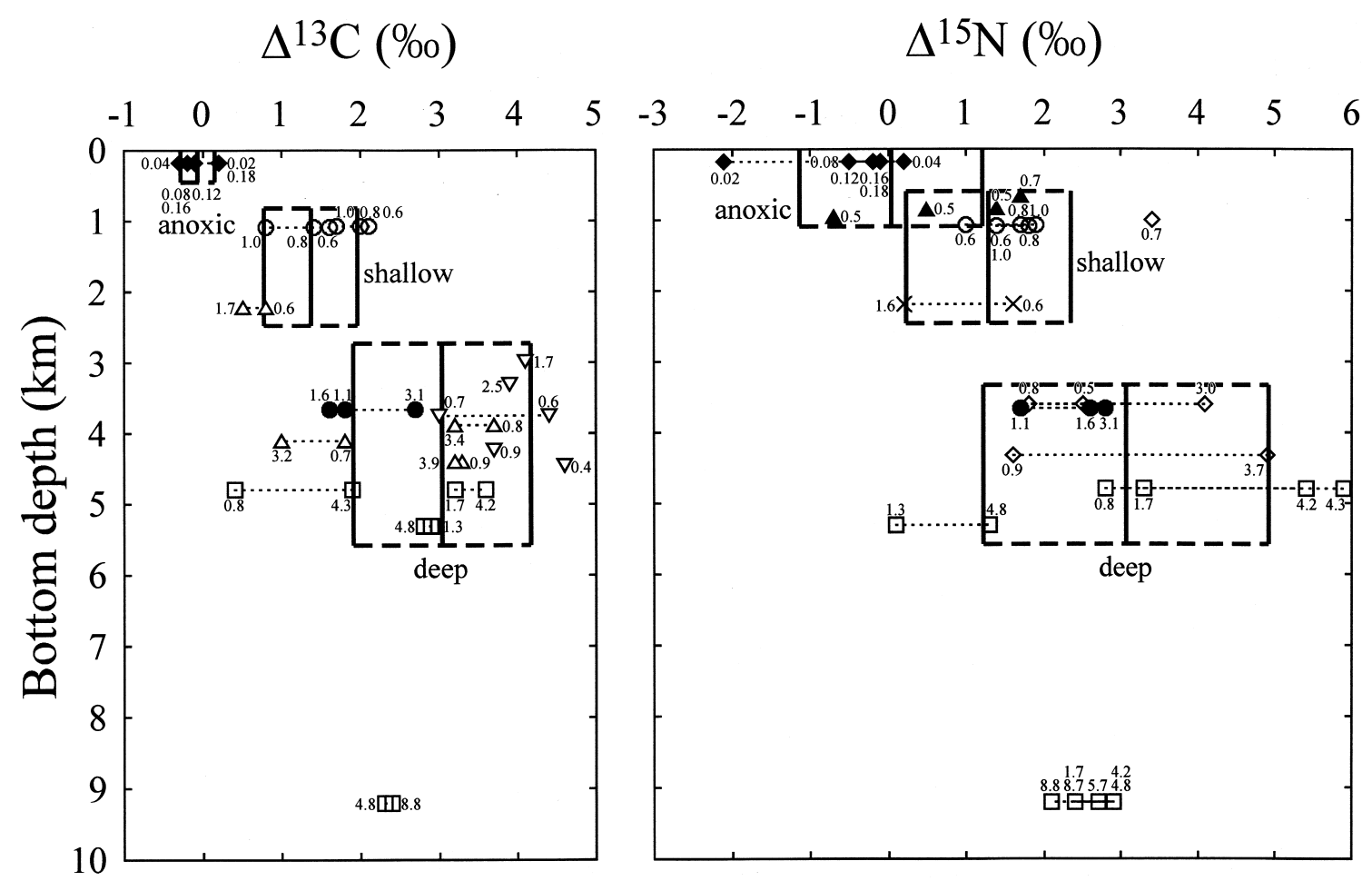

Fig. 7. The compilation of previously reported isotopic fractionation between sinking particles and the surface sediments for $\delta^{13} C$ and $\delta^{15} N\left(\Delta^{13} C\right.$ and $\Delta^{15} N$, respectively $)$. Marks denote literature: Fischer and Wefer, $1996(\triangle)$;

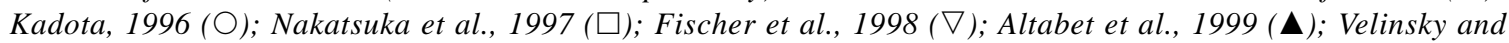
Fogel, $1999(\diamond)$; Freudenthal et al., $2001(\diamond)$; Holmes et al., $2002(\times)$; this study $(\bullet)$. The horizontal variation with same marks in the figure shows the variation of $\Delta$ due to different collection depth of sinking particles. Suffixes near points indicate the trap depth $(\mathrm{km})$. Boxes consist of average (center line), standard deviation (side lines) and depth range (dashed lines).

showed latitudinal trend reflecting the $\delta^{13} \mathrm{C}$ of phytoplankton (Goericke and Fry, 1994). For instance, $\delta^{13} \mathrm{C}$ and $\delta^{15} \mathrm{~N}$ of surface sediments varied from -26 to $-18 \%$, and from 2 to $16 \%$ respectively, depending on the difference of environments. To compare the magnitude of isotope discrimination between sinking particles and sediments at various regions, we took the isotopic change $(\Delta)$ between sinking particles and surface sediment at the same location (Fig. 7). The $\Delta$ showed relatively smaller variations; -0.2 to $+4.6 \%$ for $\delta^{13} \mathrm{C}$ and -2.1 to $+5.9 \%$ or for $\delta^{15} \mathrm{~N}$ respectively. Moreover, $\Delta$ appeared to increase with the bottom depth from surface to $5300 \mathrm{~m}$, even though excluded the data set from anoxic loca- tions (Fig. 7). The mean $\Delta$ value in bottom depth shallower than $2200 \mathrm{~m}$ was $+1.4 \pm 0.6$ and $+1.3 \pm$ $1.1 \%$ for $\delta^{13} \mathrm{C}$ and $\delta^{15} \mathrm{~N}$ respectively, and in the bottom depth between $3000 \mathrm{~m}$ to $5300 \mathrm{~m}$ the $\Delta$ was $+3.0 \pm 1.1$ and $+3.1 \pm 1.8 \%$ or $\delta^{13} \mathrm{C}$ and $\delta^{15} \mathrm{~N}$ respectively. The $\Delta$ in the Japan Sea were plotted nearly same range with the data obtained at the open sea which bottom depth are between $3000 \mathrm{~m}$ to $5300 \mathrm{~m}$. Hence $\Delta$ of both carbon and nitrogen seems to increase with the bottom depth. Even though the data set shallower than $900 \mathrm{~m}$ is from the anoxic locations, the $\Delta$ at deeper range (3000$5300 \mathrm{~m}$ ) are significantly enriched heavy isotopes than that of middle range $(900-2200 \mathrm{~m})$. The $\Delta$ is not always functional with the sinking depth, as 
denoted by suffixes in Fig. 7 and already noted in the paragraph before, suggesting that decomposition of organic matter in sinking process may not be a major reason to result the vertical trend of $\Delta$ in Fig. 7. The most likely factor this vertical trend on $\delta^{13} \mathrm{C}$ and $\delta^{15} \mathrm{~N}$ can be ascribed to the difference of organic matter preservation. Generally sedimentary organic matter is well preserved in the site where sedimentation rate is relatively high (Heinrich and Reeburgh, 1987). In such conditions its isotope fractionation on diagenesis would be relatively small (Altabet et al., 1999). Because a particulate flux and/or sedimentation mass flux is larger in the offshore location than those at the open sea, the sedimentary organic matter at shallower location should be preserved better than that in open sea. Due to this effect, the $\Delta$ at the deep sites has relatively higher than the middle depth (900-2200 m) locations. Another likely reason may be ascribed to the difference of trapping efficiency of lateral organic matters between in marginal sea (shallower) and the pelagic sites (deeper). Because allochthonous substances are often transported near marginal seas as a sporadic event, suggesting that sediment trap which is even a year round deployments possible to miss the contribution of allochthonous organic matter. If such substances are originated from terrestrial area, the contribution of such effect might defuse the bulk isotopic shift at the bottom surface. As there is no evidence to certify this possibility now, not only bulk isotope analyses, but it is important to apply also simultaneous approach using biomarkers indicating terrestrial organics such as lignin. It seems that the data from the sites shallower than $900 \mathrm{~m}$ show common trend, however, it is not clear if organic matter decomposition in anoxic locations take place with same isotope fractionation. Hence further consideration need in future to evaluate this process.

\section{Paleoceanographic implications}

Previous report working on organic matter in the sediment core issued that chronological variation of $\delta^{13} \mathrm{C}$ and $\delta^{15} \mathrm{~N}$ should be attributed to the result of mixing with terrestrial and marine organic matters (Minoura et al., 1997). However our study lays emphasis that two considerable factors could be important for causing isotopic variations in sediment. Firstly, $\delta^{13} \mathrm{C}$ and $\delta^{15} \mathrm{~N}$ in sinking particles fluctuated mainly by the balance of intensity of primary production and the nutrient supply by mixing. This process has been before known in previous works, but we showed that this factor could be major reason resulting $\delta^{13} \mathrm{C}$ and $\delta^{15} \mathrm{~N}$ fluctuation in the Japan Sea. For example, Oba and Akasaka (1990) suggested that primary productivity would be lower in the last glacial maximum because of the low organic carbon contents. If this estimation is the case, it is hypothesized that the significantly low $\delta^{13} \mathrm{C}$ and $\delta^{15} \mathrm{~N}$ observed in LGM might be resulted due to replete nutrient abundance. Secondly, we showed that the isotopic effect on early diagenesis in the surface sediment is important factor to reconstruct $\delta^{13} \mathrm{C}$ and $\delta^{15} \mathrm{~N}$ of plankton in geological time period. Masuzawa and Kitano (1984) suggested that bottom water in the last glacial maximum was anoxic as recorded bearing $\mathrm{H}_{2} \mathrm{~S}$. This means that the $\Delta$ values for $\delta^{13} \mathrm{C}$ and $\delta^{15} \mathrm{~N}$ might be small in that age whereas $\delta^{13} \mathrm{C}$ and $\delta^{15} \mathrm{~N}$ in Holocene could be deviated to more positive direction. This isotopic deviation must be necessary to correct the end-member values for applying it isotope mass balance model. If we could successfully estimate the isotopic composition of primary producer, it is possible to estimate the $\delta^{15} \mathrm{~N}$ of nitrate in seawater in different geological periods. It should be emphasized that the result in Fig. 7 suggests that such correction can change $\delta^{13} \mathrm{C}$ and $\delta^{15} \mathrm{~N}$ as much as 4 and 7 per mil as in maximum, respectively.

Even these data analysis might be considered, $\delta^{13} \mathrm{C}$ and $\delta^{15} \mathrm{~N}$ of organic matter are not always unique for any primary producers, so we needs other proxies that can indicate an end-members independently. From such viewpoints, we are analyzing some biomarkers in lipid fraction of sinking particles and sediments to represent both marine plankton and terrestrial matter. It will give better understanding in future about the origin and mixing of organic fractions in the Japan Sea. 


\section{Conclusions}

The carbon and nitrogen isotopic compositions in sinking particles recorded the seasonal variation of surface environment in the northeast Japan Sea. The carbon isotopic ratio in POC varied reflecting the difference between the growth rates of phytoplankton. The high $\delta^{13} \mathrm{C}$ of sinking particle were found in late autumn and early summer when the primary production showed maxima. On the other hand, the $\delta^{15} \mathrm{~N}$ varied depending on surface nutrient budget by vertical mixing. From winter to spring, the nitrate concentration in the surface layer increases and favors the isotope fractionation during the phytoplankton uptake. Thus, the temporal variations of $\delta^{13} \mathrm{C}$ and $\delta^{15} \mathrm{~N}$ will be good corresponded with blooming and its factor.

Both carbon and nitrogen isotopic ratios of sinking particle were not considerably influenced by early decomposition during the sinking, even though the $\mathrm{C} / \mathrm{N}$ ratio has changed dramatically. Carbon and nitrogen isotopic discrimination between sinking particles and the surface sediment, however, found to be significantly large as much as reported in previous works in the open sea. Based on the data compilation of previously reported results we estimated that carbon and nitrogen isotopic discriminations between sinking particles and the surface sediment; $\Delta{ }^{13} \mathrm{C}$ and $\Delta{ }^{15} \mathrm{~N}$, are 1.4 and $1.3 \%$ in the shallow region (900-2200 $\mathrm{m})$, respectively, and 3.0 and $3.1 \%$ in the deep region (3000-5300 m), respectively. Finally we emphasize that $\Delta^{13} \mathrm{C}$ and $\Delta^{15} \mathrm{~N}$ are controlled mainly by the bottom depth and the discrimination in the particle sinking process seems to be an optional factor depending on the water condition. Further researches in future are necessary to make this role more detail.

Acknowledgments-We thank the scientists, Captain, officers and crew aboard the R/V Hakuho-Maru cruises KH98-3 and KH99-4 for their kind help in the samplings. We thank H. Hattori in Department of Chemistry, Graduated School, Kinki University, K. Isshiki in Department of Environmental Science, Kochi Women's University and other members for the nutrient and chlorophyll $a$ analyses on the board. Thanks are also due to Drs. H. Amakawa in Graduate School of Sciences, Tokyo Metropolitan University, H. Narita, T. Kuramoto and Mr. Y. Nakajima in Graduate School of Environmental Earth Science, Hokkaido University for their technical assistance with sampling in the KH98-3 and KH99-4 cruises. We are indebted to Dr. S. J. Kao, National Center for Ocean Research, for his valuable suggestions.

\section{REFERENCES}

Altabet, M. A. (1988) Variations in nitrogen isotopic composition between sinking and suspended particles: implications for nitrogen cycling and particle transformation in the open ocean. Deep-Sea Res. 35, $535-554$.

Altabet, M. A. and Francois, R. (1994) Sedimentary nitrogen isotopic ratio as a recorder for surface ocean nitrate utilization. Glob. Biogeochem. Cycles 8, 103116.

Altabet, M. A., Deuser, W. G., Honjo, S. and Stienen, C. (1991) Seasonal and depth-related changes in the source of sinking particles in the North Atlantic. Nature 354, 136-139.

Altabet, M. A., Pilskaln, C., Thunell, R., Pride, C., Sigman, D., Chavez, F. and Francois, R. (1999) The nitrogen isotope biogeochemistry of sinking particles from the margin of the Eastern North Pacific. Deep-Sea Res. I 46, 655-679.

Checkley, D. M. and Entzeroth, L. C. (1985) Elemental and isotopic fractionation of carbon and nitrogen by marine, planktonic copepods and implications to the marine nitrogen cycle. J. Plankton Res. 7, 553568.

Checkley, D. M. and Miller, C. A. (1986) Nitrogen isotope fractionation by oceanic zooplankton. EOS 67, 988.

Farrell, J. W., Pedersen, T. F., Calvert, S. E. and Nielsen, B. (1995) Glacial-interglacial changes in nutrient utilization in the equatorial Pacific Ocean. Nature 377, 514-517.

Fischer, G. and Wefer, G. (1996) Long-term observation of particle fluxes in the eastern Atlantic: seasonality, changes of flux with depth and comparison with the sediment record. The South Atlantic: Present and Past Circulation (Wefer, G., Berger, W. H., Siedler, G. and Webb, G., eds.), 325-344, Springer-Verlag, Berlin.

Fischer, G., Muller, P. J. and Wefer, G. (1998) Latitudinal $\delta^{13} \mathrm{C}_{\text {org }}$ variations in sinking matter and sediments from the South Atlantic: effects of anthropogenic $\mathrm{CO}_{2}$ and implications for paleo- $\mathrm{PCO}_{2}$ reconstructions. J. Mar. Syst. 17, 471-495. 
Francois, R., Altabet, M. A., Yu, E. F., Sigman, D. M., Bacon, M. P., Frank, M., Bohrmann, G., Bareille, G. and Labeyrie, L. D. (1997) Contribution of Southern Ocean surface-water stratification to low atmospheric $\mathrm{CO}_{2}$ concentrations during the last glacial period. Nature 389, 929-935.

Freudenthal, T., Neuer, S., Meggers, H., Davenport, R. and Wefer, G. (2001) Influence of lateral particle advection and organic matter degradation on sediment accumulation and stable nitrogen isotope ratios along a productivity gradient in the Canary Islands region. Mar. Geol. 177, 93-109.

Fry, B. (1988) Food web structure on George Bank from stable C, N, and S isotopic compositions. Limnol. Oceanogr. 33, 1182-1190.

Gamo, T., Nozaki, Y., Sakai, H., Nakai, T. and Tsubota, H. (1986) Spatial and temporal variations of water characteristics in the Japan Sea bottom water. J. Mar. Res. 44, 781-793.

Goericke, R. and Fry, B. (1994) Variations of marine plankton $\delta^{13} \mathrm{C}$ with latitude, temperature, and dissolved $\mathrm{CO}_{2}$ in the world ocean. Glob. Biogeochem. Cycles 8, 85-90.

Henrichs, S. M. and Reeburgh, W. S. (1987) Anaerobic mineralization of marine sediment organic matter: rates and the role of anaerobic processes in the oceanic carbon economy. Geomicrobiol. J. 5, 191-237.

Hirakawa, K., Morita, A., Nagata, H. and Hirai, M. (1999) Seasonal variability of the zooplankton assemblage and its relationship with oceanographic structures at Yamato Tai, central Japan Sea. Bull. Japan Sea Natl. Fish. Res. Inst. 49, 37-56 (in Japanese with English abstract).

Holmes, E., Lavik, G., Fischer, G., Segl, M., Ruhland, G. and Wefer, G. (2002) Seasonal variability of $\delta^{15} \mathrm{~N}$ in sinking particles in the Benguela upwelling region. Deep-Sea Res. I 49, 377-394.

Ishiwatari, R., Hirakawa, Y., Uzaki, M., Yamada, K. and Yada, T. (1994) Organic geochemistry of the Japan Sea sediments-1: bulk organic matter and hydrocarbon analyses of Core KH-79-3, C-3 from the Oki Ridge for paleoenvironment assessments. $J$. Oceanogr. 50, 179-195.

Iwasaka, Y., Minoura, H. and Nagaya, K. (1983) The transport and special scale of Asian dust-storm clouds: a case study of the dust-storm event of April 1979. Tellus 35B, 189-196.

Jasper, J. P., Hayes, J. M., Mix, A. C. and Prahl, F. G. (1994) Photosynthetic fractionation of ${ }^{13} \mathrm{C}$ and concentrations of dissolved $\mathrm{CO}_{2}$ in the central equatorial Pacific during the last 255,000 years. Paleoceanogr. 9, 781-798.

Kadota, Y. (1996) Mass transportation of particulate organic matter in East China Sea detected by their flux, carbon and nitrogen isotope ratios. Master's Thesis, Hokkaido Univ., 79 pp. (in Japanese).

Kim, S. W., Saitoh, S., Ishizaka, J., Isoda, Y. and Kishino, M. (2000) Temporal and spatial variability of phytoplankton pigment concentrations in the Japan Sea derived from CZCS images. J. Oceanogr. 56, 527-538.

Laws, E. A., Popp, B. N., Bidigare, R. R., Kennicutt, M. C. and Macko, S. A. (1995) Dependence of phytoplankton carbon isotopic composition on growth rate and $\left[\mathrm{CO}_{2}\right]_{\mathrm{aq}}$ : theoretical considerations and experimental results. Geochim. Cosmochim. Acta 59, 1131-1138.

Mariotti, A., Germon, J. C., Hurbert, P., Kaiser, P., Letolle, R., Tardieux, A. and Tardieux, P. (1981) Experimental determination of nitrogen kinetic isotope fractionation: some principles; illustration for the denitrification and nitrification processes. Plant Soil 62, 413-430.

Masuzawa, T. and Kitano, Y. (1984) Appearance of $\mathrm{H}_{2} \mathrm{~S}$ bearing bottom waters during the last glacial period in the Japan Sea. Geochem. J. 18, 167-172.

Minagawa, M. and Nakanishi, T. (2000) Paleoceanographic change of nitrogen cycling in Japan Sea during last 80,000 years inferred from carbon and nitrogen isotopic analyses of sedimentary organic matters. Program \& Abstracts, AGU 2000 Fall Meeting, 657.

Minagawa, M. and Wada, E. (1984) Stepwise enrichment of ${ }^{15} \mathrm{~N}$ along food chains: further evidence and the relation between $\delta^{15} \mathrm{~N}$ and animal age. Geochim. Cosmochim. Acta 48, 1135-1140.

Minoura, K., Hoshino, K., Nakamura, T. and Wada, E. (1997) Late Pleistocene-Holocene paleoproductivity circulation in the Japan Sea: sea-level control on $\delta^{13} \mathrm{C}$ and $\delta^{15} \mathrm{~N}$ records of sediment organic material. Palaeo. 135, 41-50.

Montoya, J. P. and McCarthy, J. J. (1995) Isotopic fractionation during nitrate uptake by phytoplankton grown in continuous culture. J. Plankton Res. 17, 439-464.

Nagata, H. (1993) A phytoplankton bloom recorded in a long-term monitoring of chrolophyll $a$ concentration in the Japan Sea. Bull. Plankton Soc. Japan 39, 145-147.

Nakanishi, T. and Minagawa, M. Seasonal variability of biomarkers in sinking particles in the Japan Sea (in preparation).

Nakatsuka, T. and Handa, N. (1997) Reconstruction of seasonal variation in nutrient budget of a surface mixed layer using $\delta^{15} \mathrm{~N}$ of sinking particle collected by a time-series sediment trap system. J. Oceanogr. 53, 105-116.

Nakatsuka, T., Watanabe, K., Handa, N., Matsumoto, 
E. and Wada, E. (1995) Glacial to interglacial surface nutrient variations of Bering deep basins recorded by $\delta^{13} \mathrm{C}$ and $\delta^{15} \mathrm{~N}$ of sedimentary organic matter. Paleoceanogr. 10, 1047-1061.

Nakatsuka, T., Handa, N., Harada, N., Sugimoto, T. and Imaizumi, S. (1997) Origin and decomposition of sinking particulate organic matter in the deep water column inferred from the vertical distributions of its $\delta^{15} \mathrm{~N}, \delta^{13} \mathrm{C}$ and $\delta^{14} \mathrm{C}$. Deep-Sea Res. I 44, 1957-1979.

Nozaki, Y. (1998) Preliminary Report of Hakuho Maru Cruise KH98-3. Ocean Research Institute, Univ. of Tokyo, 133 pp.

Oba, T. and Akasaka, N. (1990) Paleoenvironmental change of the Japan Sea based on organic carbon contents of two piston cores. Quat. Res. 29, 417-425 (in Japanese with English abstract).

Oba, T., Kato, M., Kitazato, H., Koizumi, I., Omura, A., Sakai, T. and Takayama, T. (1991) Paleoenvironmental changes in the Japan Sea during the last 85,000 years. Paleoceanogr. 6, 499-518.

Ohashi, M. (1999) The origin of nitrogen in the marginal sea using stable isotope analysis. Master's Thesis, Hokkaido Univ., 73 pp. (in Japanese).

Okumura, S., Minagawa, M., Oba, T. and Ikehara, K. (1996) Paleoenvironmental analysis of two sediment cores off Akita City in the Japan Sea based on oxygen, carbon and nitrogen isotopes. Quat. Res. 35, 349-358 (in Japanese with English abstract).

Parsons, T. R., Takahashi, M. and Hargrave, M. (1984) Biological Oceanographic Processes. 3rd ed., Pergamon Press, Oxford, $330 \mathrm{pp.}$

Rau, G. H., Takahashi, T. and Des Marais, D. J. (1989) Latitudinal variations in plankton $\delta^{13} \mathrm{C}$ : implications for $\mathrm{CO}_{2}$ and productivity in past oceans. Nature 341,
516-518.

Senjyu, T. (1999) The Japan Sea Intermediate Water; Its characteristics and circulation. J. Oceanogr. 55, 111-122.

Sigman, D. M., Altabet, M. A., Francois, R., McCorkle, D. C. and Gaillard, J. F. (1999) The isotopic composition of diatom-bound nitrogen in Southern Ocean sediments. Paleoceanogr. 14, 118-134.

Stein, R. (1991) Accumulation of Organic Carbon in Marine Sediments. Springer-Verlag, Berlin, 217 pp.

Tada, R., Irino, T. and Koizumi, I. (1999) Land-ocean linkages over orbital and millennial timescales recorded in late Quaternary sediments of the Japan Sea. Paleoceanogr. 14, 236-247.

Terazaki, M. (1999) Preliminary Report of Hakuho Maru Cruise KH99-4. Ocean Research Institute, Univ. of Tokyo, $37 \mathrm{pp}$.

Velinsky, D. J. and Fogel, M. L. (1999) Cycling of dissolved and particulate nitrogen and carbon in the Framvaren Fjord, Norway: stable isotopic variations. Mar. Chem. 67, 161-180.

Wada, E. and Hattori, A. (1978) Nitrogen isotope effects in the assimilation of inorganic nitrogenous compounds by marine diatoms. Geomicrobiol. J. 1, 85-101.

Wada, E., Terazaki, M., Kabaya, Y. and Nemoto, Y. (1987) ${ }^{15} \mathrm{~N}$ and ${ }^{13} \mathrm{C}$ abundances in the Antarctic Ocean with emphasis on the biogeochemical structure of the food web. Deep-Sea Res. 34, 829-841.

Wu, J., Calvert, S. E., Wong, C. S. and Whitney, F. A. (1999) Carbon and nitrogen isotopic composition of sedimenting particulate material at Station Papa in the subarctic northeast Pacific. Deep-Sea Res. II 46, 2793-2832. 